\title{
Parenting Stress and Motor Function of Children with Cerebral Palsy
}

\section{Katiane da Costa Cunha, Fernando Augusto Ramos Pontes, Simone Souza da Costa Silva}

Postgraduate Program in Theory and Research of Behavior, Federal University of Pará, Belém, Brazil

Email: katianefisio@yahoo.com.br, farp1304@gmail.com, symon.ufpa@gmail.com

How to cite this paper: da Costa Cunha, K., Pontes, F. A. R., \& da Costa Silva, S. S. (2017). Parenting Stress and Motor Function of Children with Cerebral Palsy. Psychology, 8, 44-58.

http://dx.doi.org/10.4236/psych.2017.81004

Received: September 20, 2016

Accepted: January 1, 2017

Published: January 5, 2017

Copyright $\odot 2017$ by authors and Scientific Research Publishing Inc. This work is licensed under the Creative Commons Attribution International License (CC BY 4.0).

http://creativecommons.org/licenses/by/4.0/ (c) (i) Open Access

\begin{abstract}
This study aimed to investigate the association between the stress levels of parents of children with cerebral palsy and the degree of functional impairment of their children, as well as to explore socio-demographic variables that may potentiate the effects of the motor impairment degree generating high or low/standard stress levels in 92 parents of children with cerebral palsy treated at a federal public hospital of reference in the state of Pará. The instruments used were the Socio-demographic Inventory (ISD), the Gross Motor Function Classification System (GMFCS) and the Parenting Stress Index-short form (PSI/SF). Analyses were performed using SPSS version 20.0. The results showed a greater number of stressed parents in the Difficult Child subscale and a significant relation between the children classified with severe motor impairment and the manifestation of parenting stress. This research showed an approximate age range of children with cerebral palsy in both stressed and little stressed parent groups, but the presence of younger stressed parents in the group was observed. On the other hand, in the group of little stressed parents, a significant aspect found was the prolonged time of union of thecouple at the time of birth of the child with cerebral palsy. The findings of this study intend to contribute to the increase of research about the relation between stress in parents of children with cerebral palsy and the motor function of their children, a theme poorly addressed in national and international research.
\end{abstract}

\section{Keywords}

Psychological Stress, Parents, Cerebral Palsy

\section{Introduction}

Cerebral Palsy (CP) is presented as a non-progressive disorder of motor and/or cognitive impairment. Its etiology is related to events that occurred before, 
during or after birth, especially in the first two years of life. The clinical picture of children with $\mathrm{CP}$ is variable and may include limitation of activity, mobility or visual impairments and hearing deficiency, which interfere with their neuropsychomotor development (Rosset, Santos, \& Galera, 2011).

With the confirmation of CP diagnosis, children need to be subjected to various forms of assessment depending on the variable pattern of cerebral palsy, but it is known that once observed abnormal muscle tone (e.g., hypertension, hypotonia), and diagnosed the movement disorders (spasticity, ataxia, dystonia, athetosis), the cerebral palsy can be classified into four types, according to the European classification of cerebral palsy: (a) spastic type, characterized by the presence of at least two of the following: Abnormal patterns of posture and/or movement, increased muscle tone (not necessarily constant), pathological reflexes, hyperreflexia and/or pyramidal signs; (b) ataxic type, characterized by abnormal patterns of posture and/or movement, loss of coordination, and change in force, rhythm and metria of movement; (c) dyskinetic type, characterized by abnormal patterns of posture and/or involuntary, uncontrolled, recurrent and occasionally stereotyped movements (Cans, 2000). According to Oliveira, Golin and Cunha (2010), the CP can also be classified according to the topographic distribution in hemiparesis (which compromises one side of the body), diparesis (more frequently in lower members) and tetraparesis (overall impairment of the four members).

In addition to the investigation of the motor impairment, the functional assessment is another relevant aspect of clinical practice and scientific research involving children with CP. The verification of functionality allows multidisciplinary teams to measure several clinical types and observed changes, ensuring accurate detection of the child's motor potential, leading to greater therapeutic efficacy (Oliveira et al., 2010; Zonta, Junior, \& Helena, 2011).

Currently there is a scientific tendency to use the degree of functional impairment through scales as a classifying measure, especially the Gross Motor Function Classification System (GMFCS). The GMFCS is a graded scale of the gross motor function of children with cerebral palsy. Its categorization goes from level 1 (lower functional impairment) to Level 5 (most severe form of CP) (Palisano, Rosenbaum, Bartlett, \& Livingston, 2008).

The GMFCS is widely used because once children are classified in a level, they tend to remain in it over time, ensuring the reliability of this instrument (Chagas et al., 2008). The use of this scale allows an unified communication between professionals, while it reduces the subjectivity at the time of cerebral palsy classification (Pfeifer, Silva, Funayama, \& Santos, 2009). Moreover, the GMFCS enables the setting of objectives appropriate to the age and functional level, providing an individual care in which the potential of motor development is respected (Hiratuka, Matsukura, \& Pfeifer, 2010) and the goals for the acquisition of the possible functional skills are established.

In cerebral palsy, the motor impairment is extremely variable. This implies that the necessary care demands will depend on the degree of impairment and 
the individual characteristics (Ribeiro, Porto, \& Vandenberghe, 2013). In this sense, the birth of a child diagnosed with cerebral palsy has the potential to change the family routine, triggering feelings of denial, sadness and guilt in the parental figures who need to learn to face the limitations of their children (Carvalho, Rodrigues, Silva, \& Oliveira, 2010). This situation, according to Freitas, Carvalho, Leite and Haase (2005), can cause physical and emotional overload on parents, triggering stress. The stress experienced by the parents is in response to difficulties in parent-child relationships during the performance of the parental role, resulting in social isolation and lack of resources to deal with potentially stressful situations (Abidin, 1992). Thus, a child's family's reaction to the diagnosis of $\mathrm{CP}$ and the parenting stress levels will be variable and multidetermined (Ribeiro et al., 2013).

There are many factors that can interfere with the manifestation of stress in parents of children with cerebral palsy. Among them are the characteristics of their children, such as behavioral problems and severity of the $\mathrm{CP}$. In this direction, Butcher, Wind and Bouma (2008) conducted a study with 108 parents of children with $\mathrm{CP}$ in order to evaluate the association between motor and behavioral problems in children with CP (hemiplegia) and the symptoms of stress in their parents. The findings revealed that the behavioral problems and the low motor performance of the child increase the levels of parenting stress. The same result was found in the longitudinal study conducted by Sipal, Schuengel, Voorman, Van Eck and Becher (2010) with 110 parents of children with $\mathrm{CP}$, which showed that the higher the motor impairment was, the higher the stress levels experienced bythe parents.

Although some research show a strong association between parenting stress in parents of children with cerebral palsy and the degree of functional impairment of their children, there is no consensus in the area. Parkes, Caravale, Marcelli, Franco and Colver (2011) described the stress in 818 parents of children with cerebral palsy and investigated the factors associated with the high rates and stress. The Parenting Stress Index and the Gross Motor Function Scale were used. The research showed that the risk factors for high blood pressure were found in parents of children with pain, intellectual disabilities and communication problems. There was no correlation between motor impairment and high levels of stress.

Finally, even if it was important, parenting stress within the family of children with cerebral palsy has not received much attention in Brazil and in the world (Ribeiro et al., 2013). In the few published Brazilian studies, the literature shows no consensus on the relation between parenting stress and the level of motor functional classification, which indicates the need to investigate other variables that, associated with the functional impairment level of the child, may act potentiating the effects of stress. In this sense, this research aims to (a) investigate whether there is an association between the stress levels of parents of children with cerebral palsy and the degree of functional impairment of their children and (b) research socio-demographic variables and factors related both 
to the high level of stress and the low/standard level of stress in parents of children with cerebral palsy.

\section{Methods}

Cross-sectional and descriptive study, whose data was collected between January and December 2014 in the city of Belém, state of Pará.

\subsection{Participants}

Participated in this study 92 parents of children diagnosed with cerebral palsy (ICD-10-G80), eight of them classified in level I of the GMFCS, eight in level II, 14 in level III, 22 in level IV and 40 in level V. The participants were parents of children with cerebral palsy who received care at the place of research from January 2014 to January 2015, the data collection being closed when it was realized the lack of new participants. Of these, three were responsible for children aged from 0 to $1.9,45$ for children between 2 and 6.9 and 44 for children aged 7 to 12 years old.

\subsection{Place of Data Collection}

The research took place individually in the waiting room of a reference service offered by a universitary hospital in Belém, Pará. This service consists of a multidisciplinary team (doctors, psychologists, pediatricians, nutritionists, social workers, nurses, physiotherapists, speech therapists, occupational therapists, neurologists and homeopath) and was founded in 2002. The choice of this service as the research location was due to the fact that it is a place of reference in the Amazon region for the diagnosis and monitoring of children of up to 12 years of age presenting growth and developmental disorders (cerebral palsy, genetic syndromes, epilepsy, etc.).

\subsection{Instruments}

The instruments used were the Socio-demographic Inventory (ISD), the Gross Motor Function Classification System (GMFCS-Palisano et al., 1997) and the Parenting Stress Index in the Short Form (PSI/SF-Abidin, 1983). The ISD, instrument built by the team of researchers from the Laboratory of Ecology of Development-Cerebral Palsy, aimed to characterize the investigated families and the children with cerebral palsy. Thus, it was structured by items related to socioeconomic aspects, history and composition of the family, and characteristics of the child and the caregiver.

The GMFCS was used to assess the functional motor impairment in children with cerebral palsy. It is structured considering four age groups ( 0 to 2 years, 2 to 4 years, 4 to 6 years and 6 to 12 years). This instrument is based on the child's voluntary movement, emphasizing the act of sitting, the transfers, and the mobility. The results generated by GMFCS are organized into five levels: Level I-walks without limitation, Level II-walks with limitations, level III-walks using a handheld device mobility, level IV-self mobility with limitations; may use 
motorized mobility, and level V-transported in a manual wheelchair. This system considers as the main criterion that the distinctions between the rating levels need to be significant in daily life (Palisano et al., 2008).

The PSI was applied in order to assess the level of stress perceived by parents. This research used a reduced version (PSI/SF-Abidin, 1983), consisting of 36 items, validated by Santos (1997), for the population of Portugal. The PSI/SF is used in research worldwide to assess the stress on parents, including research with parents of children with cerebral palsy (Ribeiro, Sousa, Vandenberghe, \& Porto, 2014). In Brazil, the instrument was translated and have been used in doctoral thesis (Minetto, 2010) and scientific article (Pereira-Silva \& Dessen, 2006). This test covers the Total Stress and three subscales (Parental Distress, Parent-Child Dysfunctional Interaction and Difficult Child). The sum of the points assigned to each item sets the total score, which can range from a minimum of 36 points to a maximum of 180 points. The cutoff point for the clinical stress level is above 94 points in the total stress. The cutoff point is above 33 in the Parental Distress subscale, above 28 in the Parent-Child Dysfunctional Interaction subscale and above 37 in the Difficult Child subscale. The high results may indicate the need for further evaluation and referral for clinical intervention. For each question investigated, there is a set of options on a Likert scale of five items ( $1=$ strongly disagree to $5=$ strongly agree).

\subsection{Ethical Considerations and Collection Procedure}

This study was approved by the Ethics Committee inResearch with human beings of the Federal University of Pará (UFPA), expressed in the opinion 413.140/11.2013, with participation conditioned to the signing of the Consent and Informed (IC) of the respondent. Initially, caregivers were informed about the research objectives and those who agreed were submitted to answer the questions of the ISD and then the PSI/SF. The length of time averaged 30 minutes.

For the evaluation of the GMFCS, it was considered the best level of representation of the current skills of the child and the limitations in motor function. In order to do this, the child was evaluated by a researcher with a background in physiotherapy on the need for assistive technology, use of walking aids (walkers, crutches) and wheelchair. Caregivers were asked about the usual performance of the child at home, school and community spaces.

\subsection{Data Analysis}

After the application of the instruments, the data were entered into the statistical package SPSS version 20.0, in which all analyzes were carried out. For the analysis of PSI it was evaluated the number distribution and percentage of parents with levels of stress lower, equal or above the cutoff point in each subscale and in Total Stress through the Equality of Two Proportions test, followed by the frequency of participants of the Total Stress of PSI/SF, according to the GMFCS level groups (mild impairment, moderate impairment and severe 
impairment).

Then, in order to explore the socio-demographic variables associated with different levels of stress, the data were divided into two groups: (1) participants with high levels of stress and (2) participants with low/standard levels of stress. In both cases, a cross between quantitative variables and levels of GMFCS was performed. Finally, logistic regression was performed to see if there is a predictor variable of ISD of high stress and low/standard parenting stress.

\section{Results}

Parametric statistical tests were used because the data is quantitative and continuous. In addition, this research presents a sampling of more than 30 subjects which, according to the Central Limit Theorem, ensures that the distribution tend to a Normal distribution. Thus, there was no need to test the normality of residue, being the parametric tests directly used, as they are more powerful than non-parametric tests (Dancey \& Reidy, 2006).

On the total of 92 parents of children with cerebral palsy investigated it was observed: a predominance of female caregivers (98.0\%), predominantly monthly household income of more than 1 to 2 minimum wages (43.0\%) and beneficiaries of government welfare programs (84.9\%). As for the frequency of care received in the research institution, it could be seen that $28.0 \%$ of caregivers attended the institution weekly, while $25.8 \%$ attended monthly and $46.2 \%$ attended bi-monthly or semi-annually.

Table 1 shows the relative frequency distribution of 92 participants in each subscale and the Total Stress of PSI/SF. The categorization was based on cut-off values established in each instrument's directions. It was used the Two Proportion Equality test.

It is observed in Table 1 that only the item Parental Distress was not statistically significant $(n=42 ; p=0.238)$, although most stressed parents belonged in this subscale. In addition, there was a higher percentage of low stress on all items: Parental Distress (54.3\%), Dysfunctional Interaction (59.8\%), Difficult Child (subscale with the highest number of little stressed parents-88.0\%) and Total Stress (63.0\%). Table 1 also shows that in Total Stress, 37.0\% of mothers were stressed.

Table 1. Distribution of number and percentage of primary caregivers with PSI/SF in each subscale and Total Atress.Belém-PA, $2015(\mathrm{n}=92)$.

\begin{tabular}{cccccc}
\hline & \multicolumn{2}{c}{ Low/Standard } & \multicolumn{2}{c}{ High $\geq$} & \multirow{2}{*}{$\boldsymbol{P}$-value } \\
\cline { 2 - 5 } Parenting Stress Index PSI/SF & $\mathrm{N}$ & $\%$ & $\mathrm{~N}$ & $\%$ & \\
\hline Parental Distress $* 33$ & 50 & $54.3 \%$ & 42 & $45.7 \%$ & 0.238 \\
Dysfunctional Interaction ${ }^{*} 28$ & 55 & $59.8 \%$ & 37 & $40.2 \%$ & 0.008 \\
Difficult Child $* 37$ & 81 & $88.0 \%$ & 11 & $12.0 \%$ & $<0.001$ \\
Total Stress $* 94$ & 58 & $63.0 \%$ & 34 & $37.0 \%$ & $<0.001$ \\
\hline
\end{tabular}

Note: ${ }^{*}$ cutoff point for each subscale and Total Stress of the PSI/SF scale. Source: Field research. 
Then, in Table 2, the results of GMFCS levels and the Total Stress were crossed. In order to do this, we compared the stress levels with the level of GMFCS (Two Proportions Equality test) and related these two variables using the Chi-Square test. It is noteworthy that, due to the proximity of features, we decided to group the levels I and II (mild functional impairment), III (moderate functional impairment) and IV and V (severe functional impairment).

In Table 2, when analyzing in general the intersection between GMFCS and PSI/SF variables (evidenced by p-value below the table of 0.874 ), it is evident that the level of motor functional classification of the child with cerebral palsy does not determine the high or low/standard parenting stress manifestation. However, when making an analysis of the GMFCS groups with low/standard and high stress dimensions, it was observed that only the group "severe impairment" showed a significant difference $(p=0.001)$, also being the group with the largest number of stressed parents. On the other hand, the study on the "severe impairment" group showed a higher frequency of little stressed parents $(64.5 \%)$. It is noteworthy that these results may have been influenced by the small number of participants in the groups "mild impairment" and "moderate impairment".

Considering that the presence of a child with cerebral palsy can be accompanied by both high and low/standard parenting stress and that this difference may be related to some socio-demographic characteristics and other factors, we chose to study the population of parents of children with CP dividing them into two groups: (1) participants with high levels of stress and (2) participants with low/standard levels of stress.

\subsection{Participants with High Levels of Stress}

In the present study were found 34 participants classified as having high levels of stress from the 92 initial participants. On this group of parents, it was observed that their age ranged between 20 and 50 years old, of which 18 (52.9\%) were married, 18 (52.9\%) had completed high school, 29 (85, 30\%) were housewives, $16(47.10 \%)$ had an income of up to one minimum wage, and 29 parents $(85.30 \%)$ received the government Continued Benefit (Benefício de Prestação Continuada). Table 3 shows the cross between the degrees of GMFCS of the

Table 2. Frequency of participants in the Total Stress of the PSI/SF scale according to the motor functional classification degrees of the GMFCS. Belém-PA, 2015 ( $\mathrm{n}=92)$.

\begin{tabular}{|c|c|c|c|c|c|}
\hline \multirow{4}{*}{ GMFCS } & \multicolumn{4}{|c|}{ Total Stress Index by PSI/SF } & \multirow{4}{*}{$p$-value } \\
\hline & \multirow{2}{*}{\multicolumn{2}{|c|}{$\begin{array}{c}\text { Low/Standard } \\
<94\end{array}$}} & \multirow{2}{*}{\multicolumn{2}{|c|}{$\begin{array}{l}\text { High } \\
\geq 94\end{array}$}} & \\
\hline & & & & & \\
\hline & $\mathrm{N}$ & $\%$ & $\mathrm{~N}$ & $\%$ & \\
\hline Mild impairment & 10 & 62.5 & 6 & 37.5 & 0.157 \\
\hline Moderate impairment & 8 & 57.1 & 6 & 42.9 & 0.45 \\
\hline Severe impairment & 40 & 64.5 & 22 & 35.5 & 0.001 \\
\hline
\end{tabular}

Note: 94-cutoff point of Total Stress by PSI/SF; $p$-value $=0.874$ (Chi-square). Source: Field research. 
Table 3. Quantitative variables of ISD of parents with high levels of stress crossed with the functional classification levels of their children by GMFCS. Belém-PA, 2015 ( $n=34)$.

\begin{tabular}{cccccccc}
\hline ISD Variables & GMFCS & Average & Standard Deviation & CV & N & CI & $p$-value \\
\hline $\begin{array}{c}\text { Parents' } \\
\text { age (years) }\end{array}$ & Mild & 27.8 & 4 & $14 \%$ & 6 & 3.2 & \\
& Moderate & 26.3 & 5.4 & $21 \%$ & 6 & 4.3 & 0.029 \\
$\begin{array}{c}\text { Child's } \\
\text { age (years) }\end{array}$ & Mild & 5 & 7.8 & $23 \%$ & 22 & 3.3 & \\
$\begin{array}{c}\text { Time of parents' } \\
\text { union at the time }\end{array}$ & Moderate & 4.2 & 2.8 & $55 \%$ & 6 & 2.2 & \\
$\begin{array}{c}\text { of birth of the child } \\
\text { with CP (months) }\end{array}$ & Moderate & 34.8 & 1 & $24 \%$ & 6 & 0.8 & 0.009 \\
$\begin{array}{c}\text { Child's age when } \\
\text { the separation }\end{array}$ & Severe & 49.2 & 36.1 & $104 \%$ & 5 & 31.6 & 0.898 \\
$\begin{array}{c}\text { occured (months) } \\
\text { Mild }\end{array}$ & Moderate & 24 & 70.2 & $143 \%$ & 19 & 31.6 & \\
\hline
\end{tabular}

NOTE: CV: Coefficientof variation; CI: Confidence index. Source: Field research.

children of such stressed parents with the variables investigated by ISD, using the ANOVA test.

The $p$-values of Table 3 show that there is a statistically significant difference between the mean age of the caregiver and the child when crossed with GMFCS levels. Thus, in order to accurately determine in which level the difference occured, we opted for the Tukey's Multiple Comparison test ( $p$-value) to compare all levels in pairs, and these $p$-values were shown in Table 4 . In this table the necessary $p$-value is found by simply crossing the lines with the columns. Thus, it was found that at both ages (caregiver and child), the difference was between the "moderate impairment" level and the "severe impairment" level, the latter always with the highest average age. Therefore the age of both parent and child appears to be a variable that must be taken into account in stressed parents of children with moderate and severe motor functional impairment. In particular, the highest level of stress was found in young adults, parents of children placed in the last two age groups (aged between 4.2 and 7.7 years).

Continuing the analysis of Table 3 it was observed that 19 (55.8\%) parents of children classified in the "severe impairment" group maintained a marital relationship for about 49.2 months when the child with cerebral palsy was born. Of these, it is noteworthy that nine parents separated when the child was on average 27.6 months old. Although no statistical differences were found, it is an interesting fact that is worth mentioning in this work.

Finally, when performing the logistic regression, we observed that there is no variable that is statistically significant in high stress prediction, that is, there is no statistical model to predict the probability of high stress based on ISD variables. 
Table 4. p-values of Table 3.

\begin{tabular}{cccc}
\hline & & Mild & Moderate \\
\hline \multirow{2}{*}{ Parents' age } & Moderate & 0.926 & \\
& Severe & 0.145 & 0.049 \\
Child's age & Moderate & 0.850 & \\
& Severe & 0.087 & 0.019 \\
\hline
\end{tabular}

Source: Field research.

\subsection{Participants with Low/Standard Levels of Stress}

In this group were found 58 participants classified with low/standard levels of stress. On these parents, it was observed that their age ranged between 21 and 55 years old, of which 45 (77.6\%) were married, 56 (96.5\%) had only finished high school, 45 (77.6\% ) were housewives, 24 (41.3\%) had income of more than one to two minimum wages, and 49 parents $(84.5 \%)$ received the government Continued Benefit (Benefício de Prestação Continuada). Finally, the degrees of GMFCS of children of such unstressed or little stressed parents were crossed with quantitative variables of ISD, using the ANOVA test, as shown in Table 5.

Analyzing the data of Table 5, it can be seen that there is statistically significant difference in the "Time of parents' union at the time of birth of the child with $\mathrm{CP}$ " item when crossed with the degrees of GMFCS. Thus, in order to accurately determine in which level the difference occured, we performed the Tukey's Multiple Comparison test ( $p$-value) to compare all levels in pairs, and these $p$-values were shown in Table 6 . In this table the necessary p-value is found by simply crossing the lines with the columns. Thus, it was found that the difference was between the "mild impairment" degree with an average of 143.4 months in comparison with the "severe impairment" degree with an average of $65.0(p$-value $=0.047)$. Therefore, the prolonged union of the parents at the time of the child's birth seems to be an important variable in little stressed parents of children with $\mathrm{CP}$ classified with mild and severe motor functional impairment.

Finally, when performing the logistic regression, we observed that there is no variable that is statistically significant in low/standard stress prediction, that is, there is no statistical model to predict the probability of low/standard stress based on ISD variables.

\section{Discussion}

The CP diagnosis changes the family routine as it requires a number of behavioral changes to meet the child's needs. Depending on the severity of the $\mathrm{CP}$, the constant care (food, clothing, consultations, rehabilitation) for longer periods reduces the caregiver's time for themselves and their professional activities, making them feel physically and psychically overloaded, which may trigger the manifestation of stress (Castro \& Piccinini, 2002; Ribeiro et al., 2014). Therefore, the presence of a child with $\mathrm{CP}$ can be considered a situation capable of threatening the family functioning and the developmental person, which can lead to parenting stress. 
Table 5. Quantitative variables of ISD of parents withlow/standard levels of stress crossed with the functional classification levels of their children by GMFCS. Belém-PA, 2015 ( $\mathrm{n}=$ $58)$.

\begin{tabular}{|c|c|c|c|c|c|c|c|}
\hline ISD & GMFCS & Average & Standard Deviation & $\mathrm{CV}$ & $\mathbf{N}$ & CI & $p$-value \\
\hline \multirow{3}{*}{ Parents' age (years) } & Mild & 36.1 & 10.1 & $28 \%$ & 10 & 6.3 & \multirow{3}{*}{0.655} \\
\hline & Moderate & 32.4 & 8 & $25 \%$ & 8 & 5.5 & \\
\hline & Severe & 34 & 8.4 & $25 \%$ & 40 & 2.6 & \\
\hline \multirow{3}{*}{ Child's age (years) } & Mild & 5.1 & 2.5 & $48 \%$ & 10 & 1.5 & \multirow{3}{*}{0.087} \\
\hline & Moderate & 4.9 & 1.8 & $37 \%$ & 8 & 1.3 & \\
\hline & Severe & 6.9 & 3.2 & $46 \%$ & 40 & 1 & \\
\hline \multirow{3}{*}{$\begin{array}{l}\text { Time of parents' } \\
\text { union at the time } \\
\text { of birth of the child } \\
\text { with CP (months) }\end{array}$} & Mild & 134.4 & 119.2 & $89 \%$ & 10 & 73.9 & \multirow{3}{*}{0.030} \\
\hline & Moderate & 39.4 & 44.2 & $112 \%$ & 7 & 32.7 & \\
\hline & Severe & 65 & 72.4 & $111 \%$ & 38 & 23 & \\
\hline \multirow{3}{*}{$\begin{array}{l}\text { Child's age when } \\
\text { the separation } \\
\text { occured (months) }\end{array}$} & Mild & 12 & $-\mathrm{X}-$ & $-\mathrm{x}-$ & 1 & $-\mathrm{x}-$ & \multirow{3}{*}{0.864} \\
\hline & Moderate & 0 & $-\mathrm{x}-$ & $-\mathrm{x}-$ & 1 & $-\mathrm{x}^{-}$ & \\
\hline & Severe & 10.5 & 18.5 & $176 \%$ & 6 & 14.8 & \\
\hline
\end{tabular}

NOTE: CV: coefficient of variation; CI: confidence index. Source: Field Research.

Table 6. p-values of Table 5 .

\begin{tabular}{cccc}
\hline ISD & GMFCS & Mild & Moderate \\
\hline $\begin{array}{c}\text { Time of parents' union at the time of birth } \\
\text { of the child with CP (months) }\end{array}$ & Moderate & 0.051 & \\
\hline
\end{tabular}

Source: Field research.

The results of this research showed the largest number of mothers with high levels of stress in the Difficult Child subscale, which corresponds to the behavioral aspects of the children. Such data can be associated to the fact that most of these parents were caregivers of children who were in the most serious functional impairment group and, due to their important functional limitation, are dependent on their parents for almost all activities. This finding differs from the findings of Ribeiro et al. (2014) who found a higher frequency of mothers of children with cerebral palsy in the Parental Distress subscale, which deals with the stress of parents in the exercise of the parental role and the social restrictions of these parents. The authors assigned this result to the lack of time of these parents for themselves and for sociability and leisure activities.

Although present, parenting stress proved to be at low/standard levels in more than half of the parents, which is consistent with a body of literature that shows that not all families who receive a diagnosis of chronic alteration of development present high levels of stress (Gomes \& Bosa, 2004). On this matter, this study emphasized that there was a higher percentage of low stress on all subscales (Parental Distress, Dysfunctional Interaction, Difficult Child) and on the Total Stress score. 
Analyzing the relation between the three GMFCS groups (mild impairment, moderate impairment and severe impairment) and the Total Stress of PSI/SF, the data suggest that the severe motor functional impairment in children with cerebral palsy explains significantly the manifestation of parenting stress in this group. This can be explained by the high degree of dependence of these children. In general they are children who are often subjected to hospital admissions, consultations with medical staff and rehabilitation. In the specific case of families with children with $\mathrm{CP}$, emotional distress is often accompanied by financial issues, since most of the parents are overwhelmed with the daily care demands and calls and basic treatments for the child's survival and many abdicate their professional careers, limiting the family income and often depending on government assistance programs to ensure the care the child needs.

In line with this research, the study by Ribeiro et al. (2014) showed that, in general, the degree of functional impairment of cerebral palsy by the GMFCS has not been able to explain the manifestation of stress in the parent population. However, the authors found differences between the groups of children formed by those with mild and severe motor impairment. In this case it was shown that mothers of children with mild motor impairment showed higher stress level on points relative to the behavior of their children, while mothers of adolescents at levels IV and V showed stress due to the apparent high degree of dependency for activities of their children.

Likewise, in a study by Barbosa et al. (2012) aiming to relate the motor impairment (through GMFCS scale) of 12 children with cerebral palsy and the quality of life and overload of the caregiver, it was observed that the severity of the $\mathrm{CP}$ did not show predictive relation between the stress and overload of the caregiver and the quality of life reported by these children.

On the other hand, when analyzing the socio-demographic characteristics of parents of children with high and low/standard levels of stress, it can be concluded the following: the majority are female caregivers, highly stressed parents of children with CP proved to be married (52.9\%) and had completed high school in just over half the cases (52.9\%). In addition, most reported to do housework (85.3\%) and dependence on the government Continued Benefit (Benefício de Prestação Continuada) (85.3\%) to ensure the family's survival with income up to the minimum wage in almost half of cases $(47,1 \%)$. On little stressed parents it was observed that most were married (77.6\%), almost all of them had completed only high school (96.5\%), and housework was found in most cases (77.6 \%), however in lower percentage than stressed parents. Finally, almost half of them had income of more than one to two minimum wages, but also received the government Continued Benefit.

Therefore, when comparing the findings of this research with the literature, it was found that $98 \%$ of all primary caregivers were female (mother or grandmother), agreeing with the data found by Milbrath, Cecagno, Soares, Amestoy and Siqueira (2008). Moreover, as found in the research by Santos, Oliveira, Vargas and Macedo (2010), abdicating the professional careers to ensure the 
care of the child with CP (health, food, medical consultations, rehabilitation, etc.) seems to be a choice found more frequently in stressed parents.

On the education of participants, unlike the research made by Freitas, Rocha and Haase (2014), who found emotional overload on mothers with higher levels of education, this study showed that both stressed and little stressed parents completed only high school, but in the latter the percentage was higher $(96.5 \%$ of little stressed parents). One possible explanation is that these parents somehow developed coping strategies before the child's chronicity situation, which allowed them to reveal low stress.

In line with the study by Glenn, Cunningham, Poole, Reeves and Weindling (2009), stressed parents reported lower family income. This high stress level can be justified by the parental conflict of not having the financial resources necessary to guarantee the access to health and education services that the child needs. Finally, in contrast with the results obtained by Ribeiro et al. (2014), this study showed that the group of stressed parents was formed by young adult parents of children in the last two age groups of the GMFCS evaluation (Palisano et al., 1997), classified with moderate to severe motor functional impairment. These findings suggest that young adult parents perceive themselves stressed when caring for children in the age group in which the chronicity is already established, that is, at a time when the functional abilities and limitations are evident. It is possible that in these parents the feeling of impotence in face of the limitations of the children, associated with physical and emotional overload, are motivating feelings of the high stress level revealed by them.

It is noteworthy, although not an object of this research, that the literature reveals that some aspects may be present in little stressed parents: parental support (Gregorutti \& Omote, 2015), social and spousal support, satisfaction with the parental role, good family functioning, emotional bond between father/ mother and child and active social participation by the caregiver (Ribeiro et al., 2013). However, it was found no study, in addition to this research, with significant relation between the prolonged time of union of the parents when the child with CP was born and low stress. This finding may be related to the fact that the presence of the couple to share the tasks in the care of children with $\mathrm{CP}$ alleviates parental strain. Distinctively, marital stability in families of children with CP with mild and severe motor impairment seems to have been a factor that influenced the manifestation of low stress in the population studied.

\section{Conclusion}

The contribution of this study is to prove that the severe motor functional impairment in children with cerebral palsy explains significantly the manifestation of parenting stress and to identify some characteristics of the groups of stressed and unstressed parents of children with cerebral palsy. In the group of stressed parents it was found the presence of young adult parents responsible for children in the last two age groups of the GMFCS evaluation (between 4.2 and 7.7 years old), classified with moderate to severe motor functional impairment. 
While in the little stressed parents, the prolonged time of union of the parents seems to be a significant variable in the low/standard stress in parents of children with CP with mild and severe motor impairment. Finally, the findings of this study intend to contribute to the increase of research on the relation between stress in parents of children with cerebral palsy and the motor functionality of their children, a theme poorly addressed in national and international research. However, it is noteworthy that this study was limited to investigating only a reference institution. In this sense, it is suggested future research to verify the same subject in other national and international institutions in order to confirm or compare the data reported here.

\section{References}

Abidin, R. R. (1983). Parenting Stress Index: Manual, Administration Booklet, [and] Research Update. Charlottesville, VA: Pediatric Psychology Press.

Abidin, R. R. (1992). The Determinants of Parenting Behavior. Journal of Clinical Child Psychology, 21, 407-412. https://doi.org/10.1207/s15374424jccp2104_12

Barbosa, D. C., De Sousa, F. G. M., Silva, A. C. O., Silva, Í. R., Da Silva, T. P., \& Paiva, M. C. M. (2012). Overloading of Maternal Care for Children with Chronic Conditions. Cogitare Enfermagem, 17, 492-497.

Butcher, P.R., Wind, T., \& Bouma, A. (2008). Parenting Stress in Mothers and Fathers of a Child with a Hemiparesis: Sources of Stress, Intervening Factors and Long-Term Expressions of Stress. Child: Care, Health and Development, 34, 530-541. https://doi.org/10.1111/j.1365-2214.2008.00842.x

Cans, C. (2000). Surveillance of Cerebral Palsy in Europe: A Collaboration of Cerebral Palsy Surveys and Registers. Developmental Medicine \& Child Neurology, 42, 816-824. https://doi.org/10.1111/j.1469-8749.2000.tb00695.x

Carvalho, J. T. M., Rodrigues, N. M., Silva, L. V. C., \& Oliveira, D. A. (2010). Quality of Life of Mothers of Children and Adolescents with Cerebral Palsy [I]. Fisioterapia em Movimento, 23, 389-397. https://doi.org/10.1590/S0103-51502010000300006

Castro, E. D., \& Piccinini, C. A. (2002). Implications of Chronic Disease in Childhood to Family Relationships: Some Theoretical Issues. Psicologia: Reflexão e Crítica, 15, 625635. https://doi.org/10.1590/S0102-79722002000300016

Chagas, P. S. C., Defilipo, E. C., Lemos, R. A., Mancini, M. C., Frônio, J. S., \& Carvalho, R. M. (2008). Classification of Motor Function and Functional Performance of Children with Cerebral Palsy. Revista Brasileira de Fisioterapia, 12, 409-416. https://doi.org/10.1590/S1413-35552008000500011

Dancey, C. P., \& Reidy, J. (2006). Statistics without Mathematics to Psychology: Using SPSS for Windows. Porto Alegre: Artmed.

Freitas, P. M. de, Rocha, C. M., \& Haase, V. G. (2014). Analysis of Predictors of the Psychological Status of Mothers of Children with Cerebral Palsy. Estudos e Pesquisa em Psicologia, 14, 453-473. http://www.e-publicacoes.uerj.br/index.php/revispsi/article/view/12664/9855

Freitas, P. M., Carvalho, R. C. L., Leite, M. R. S. D. T., \& Haase, V. G. (2005). Relationship between Maternal Stress and the Inclusion of Children with Cerebral Palsy. Arquivos Brasileiros de Psicologia, 57, 46-57.

http://pepsic.bvsalud.org/scielo.php?script=sci_arttext\&pid=S1809-5267200500010000 $5 \& \operatorname{lng}=\mathrm{pt} \& \operatorname{tng}=\mathrm{pt}$

Glenn, S., Cunningham, C., Poole, H., Reeves, D., \& Weindling, M. (2009). Maternal Pa- 
renting Stress and Its Correlates in Families with a Young Child with Cerebral Palsy. Child: Care, Health and Development, 35, 71-78.

https://doi.org/10.1111/j.1365-2214.2008.00891.x

Gomes, V. F., \& Bosa, C. (2004). Stress and Family Relationships from the Perspective of Siblings of Individuals with Pervasive Developmental Disorders. Estudos de Psicologia (Natal), 9, 553-561. https://doi.org/10.1590/S1413-294X2004000300018

Gregorutti, C. C., \& Omote, S. (2015). Relationship between School Inclusion of Children with Cerebral Palsy and Stress of Family Caregivers. Revista Psicologia: Teoria e Prática, 17, 136-149.

http://pepsic.bvsalud.org/scielo.php?script=sci_arttext\&pid=S1516-3687201500010001 $\underline{2 \& \operatorname{lng}=\mathrm{en} \& \mathrm{t} \operatorname{lng}=\mathrm{pt}}$

Hiratuka, E., Matsukura, T. S., \& Pfeifer, L. I. (2010). Cross-Cultural Adaptation to Brazil of the Gross Motor Function Classification System into Brazilian-Portuguese (GMFCS). Revista Brasileira de Fisioterapia, 14, 537-544.

https://doi.org/10.1590/S1413-35552010000600013

Milbrath, V. M., Cecagno, D., Soares, D. C., Amestoy, S. C., \& Siqueira, H. C. H. (2008). Being a Woman, Mother of a Child with Cerebral Palsy. Acta Paulista de Enfermagem, 21, 427-431. https://doi.org/10.1590/S0103-21002008000300007

Minetto, M. D. F. J. (2010). Parenting Practices, Parental Beliefs, Parenting Stress and Family Functioning of Parents of Children with Typical and Atypical Development. Doctoral Thesis, Florianópolis: Universidade Federal de Santa Catarina. http://repositorio.ufsc.br/xmlui/handle/123456789/94159

Oliveira, A. I. A., Golin, M. O., \& Cunha, M. C. B. (2010). Applicability of the Gross Motor Function Classification System (GMFCS) in Cerebral Palsy-Literature Review. Arquivos Brasileiros de Ciências da Saúde, 35, 220-224. https://doi.org/10.7322/abcs.v35i3.85

Palisano, R., Rosenbaum, P., Bartlett, D., \& Livingston, M. (2008). Content Validity of the Expanded and Revised Gross Motor Function Classification System. Developmental Medicine \& Child Neurology, 50, 744-750. https://doi.org/10.1111/j.1469-8749.2008.03089.x

Palisano, R., Rosenbaum, P., Walter, S., Rossell, D., Wood, E., \& Galuppi Bmatsukura, T. S. (1997). Development and Reliability of a System to Classify Gross Motor Function in Children with Cerebral Palsy. Developmental Medicine \& Child Neurology, 39, 214223. https://doi.org/10.1111/j.1469-8749.1997.tb07414.x

Parkes, J., Caravale, B., Marcelli, M., Franco, F., \& Colver, A. (2011). Parenting Stress and Children with Cerebral Palsy: A European Cross-Sectional Survey. Developmental Medicine \& Child Neurology, 53, 815-821.

https://doi.org/10.1111/j.1469-8749.2011.04014.x

Pereira-Silva, N. L., \& Dessen, M. A. (2006). Families of Children with Down Syndrome: Feelings, Ways of Life and Parenting Stress. Interação em Psicologia, 10, 183-194.

https://doi.org/10.5380/psi.v10i2.7675

Pfeifer, L. I., Silva, D. B. R., Funayama, C. A. R., \& Santos, J. L. (2009). Classification of Cerebral Palsy: Association between Gender, Age, Motor Type, Topography and Gross Motor Function. Arquivos de Neuro-Psiquiatria, 67, 1057-1061. https://doi.org/10.1590/S0004-282X2009000600018

Ribeiro, M. F. M., Porto, C. C., \& Vandenberghe, L. (2013). Parenting Stress in Families of Children with Cerebral Palsy: An Integrative Review. Ciência \& Saúde Coletiva, 18, 1705-1715. https://doi.org/10.1590/S1413-81232013000600022

Ribeiro, M. F. M., Sousa, A. L. L., Vandenberghe, L., \& Porto, C. C. (2014). Parenting Stress in Mothers of Children and Adolescents with Cerebral Palsy. Revista Latino- 
Americana de Enfermagem, 22, 440-447.

https://doi.org/10.1590/0104-1169.3409.2435

Rosset, M. O. S., Santos, B. M. O., \& Galera, S. A. F. (2011). The Overload of Children with Cerebral Palsy from the Perspective of Caregivers. UNOPAR Científica Ciencias Biológicas e da Saúde, 13, 107-114.

Santos, A. A. de S., Oliveira, C. C. da C., Vargas, M. M., \& Macedo, I. de A. B. (2010). Assessment of the Overload of Caregivers of Children with Cerebral Palsy. Ciência, Cuidado e Saúde, 9, 503-509.

https://doi.org/10.4025/cienccuidsaude.v9i3.9405

Santos, S. V. (1997). Portuguese Version of Parenting Stress Index (PSI): Preliminary Validation. In M. Gonçalves (Ed.), Avaliação Psicológica: Formas e Contextos (Vol. 5, pp. 139-149). Braga: Associação dos Psicólogos Portugueses.

Sipal, R. F., Schuengel, C., Voorman, J. M., van Eck, M., \& Becher, J. G. (2010). Course of Behaviour Problems of Children with Cerebral Palsy: The Role of Parental Stress and Support. Child: Care, Health and Development, 36, 74-84.

https://doi.org/10.1111/j.1365-2214.2009.01004.x

Zonta, M. B., Júnior, A. R., \& Helena, L. (2011). Functional Assessment in Cerebral Palsy. Acta Pediátrica Portuguesa, 42, 27-32.

http://actapediatrica.spp.pt/article/view/4153/3090

Submit or recommend next manuscript to SCIRP and we will provide best service for you:

Accepting pre-submission inquiries through Email, Facebook, LinkedIn, Twitter, etc. A wide selection of journals (inclusive of 9 subjects, more than 200 journals)

Providing 24-hour high-quality service

User-friendly online submission system

Fair and swift peer-review system

Efficient typesetting and proofreading procedure

Display of the result of downloads and visits, as well as the number of cited articles

Maximum dissemination of your research work

Submit your manuscript at: http://papersubmission.scirp.org/

Or contact psych@scirp.org 